\title{
Diet preferences of herbivores at pasture
}

\author{
B Dumont* \\ Laboratoire adaptation des herbivores aux milieux, Inra, Theix, \\ 63122 Saint-Genès-Champanelle, France \\ (Received 18 January 1996; accepted 12 September 1996)
}

\begin{abstract}
Summary - Preference is the discrimination among sward components displayed by animals when given free choice. Selection is the removal of certain sward components rather than others. Testing preferences can help to understand diet selection in more complex environments. We can measure these preferences when the animals are offered different swards provided as turves or trays indoors or forming adjacent homogeneous strips at pasture. A number of experiments have recently been conducted in this way. In this review, we summarize and discuss what the animals choose to eat given a minimum of constraints. We then focus on how behavioural and vegetation constraints influence diet selection.
\end{abstract}

preference / diet selection / foraging abilities / herbivores

Résumé - Préférences alimentaires des herbivores au pâturage. L'animal exprime ses préférences alimentaires quand il se trouve dans une situation de choix non contraignante. En pratique, une telle situation existe rarement dans les conditions habituelles du pâturage. On mesure alors la sélection alimentaire qui correspond à ce que l'animal prélève. La connaissance des préférences alimentaires des herbivores devrait aider à mieux comprendre les choix que ceux-ci réalisent dans la situation complexe du pâturage. Il est possible de les mesurer quand expérimentalement, les animaux ont le choix entre des micro-placettes ou entre des couverts homogènes adjacents. Un certain nombre d'expériences ont récemment été conduites ainsi, et cette revue a pour premier objectif de rassembler et de discuter leurs résultats. Ensuite nous montrons comment, au pâturage, les contraintes liées à la structure de la végétation et aux limites des aptitudes des animaux influencent ce qu'ils sélectionnent.

préférences / sélection alimentaire / aptitudes au pâturage / herbivore

* Correspondence and reprints 


\section{INTRODUCTION}

A better understanding of how herbivores graze in heterogeneous areas will help to improve animal production and to determine the impact of these herbivores on plant species and plant community change. Diet selection in grazing herbivores has frequently been reviewed, with particular attention paid to the constraints they face at pasture (Crawley, 1983; Illius and Gordon, 1990, 1993; Provenza and Balph, 1990; Dumont, 1995; O'Reagain and Schwartz, 1995). The herbivores' feeding decisions are at least partly dictated by their will to maximize their energy balance (Optimal Foraging Theory), but as vegetation quality is extremely variable, animals may need to select specific nutrients or avoid toxins. As the chemical content of the plants consumed may not present clear visual, olfactive or gustative cues to herbivores, their capacity to learn the consequences of previous choices plays a major role in the acquisition of appropriate dietary habits (Provenza, 1995). The morphophysiological adaptations of the animals determine their capacity to digest fibres and to best utilize cell contents, and thus largely explain the different choices made between herbivore species (Hanley, 1982; Hofmann, 1989). Body size clearly dictates the grazing strategies of ruminants because it determines absolute nutrient requirements, the ability to feed selectively, as a consequence of mouth size, and to a lesser extent, the capacity to digest low quality foods (Illius and Gordon, 1987; Demment and Greenwood, 1988; Gordon and Illius, 1988).

The diet that animals select on pastures and rangelands also generally differs from that which the animals would choose if given complete freedom of choice. For example, goats' consumption ranking of grass and of seven browse species estimated from grazing observations differs from that measured in cafeteria-type trials (Nefzaoui et al, 1995). Hodgson (1979) defined pref- erence as the discrimination exerted by animals between swards or sward components when no constraints bear on their choice. Such a situation seldom occurs naturally at pasture. We then measure diet selection, which is the removal of some sward components rather than others (Hodgson, 1979). Several authors (eg, Newman et al, 1992; Parsons et al, 1994a) recently focused on this difference between preference and selection. For them, the first stage in understanding the diet animals select is to establish their preferences. Knowing their preferences makes it possible to assess the motivation or ability of animals to maintain their choice when facing constraints at pasture. In the last few years, a number of experiments have been conducted to measure preferences at pasture. In this review, we summarize and discuss what the animals choose to eat given a minimum of constraints. We then focus on how behavioural and vegetation constraints influence diet selection.

\section{DIETARY PREFERENCES AT PASTURE}

Preferences are measured in experimental conditions in which the animals are offered the different sward components provided as turves or trays indoors (eg, Illius et al, 1992; Newman et al, 1992), or forming adjacent homogeneous strips at pasture (eg, Illius and Gordon, 1990; Parsons et al, 1994a). We can note that these experimental designs allow for the characteristics inherent in the act of grazing: herbage grasping movements, force exerted to sever a bite, short movings between feeding stations. Preferences can be calculated in two ways: $i$ ) as the proportion of the total intake derived from each sward type; or ii) as the proportion of grazing time spent feeding on each patch. The latter has the advantage in that measurements are less affected by differences between the rates of grazing each sward. 
Experimental results on relative preferences or preference rankings reveal that herbivores show a very consistent attraction for certain plant species compared to others. Sheep spend around $70 \%$ of their grazing time on white clover when offered adjacent ryegrass and clover strips (Newman et al, 1994; Parsons et al, 1994a; Penning et al, 1995a). Horses consistently prefer Italian and tetraploid ryegrasses to other grasses and chicory, and prefer grasses to legumes (Archer, 1973; Hunt et al, 1989). However, herbivore species often differ in their preferences among plants. Thus, sheep's preference for white clover relative to ryegrass tends to be higher than that of goats ( $70 \mathrm{vs}$ 52\%; Penning et al, 1995a). Sheep also have a lower preference than deer for heather associated with an Agrostis/Festuca sward (9 vs $40 \%$; Clarke et al, 1995), probably due to the difference in digestion of these forages by the two species (Milne et al, 1978).

Plant structure affects preferences of herbivores. Factors such as sward height, presence of dead material, degree of stemminess, pseudostem height or tensile strength can have an effect. Sheep prefer tall patches with intermediate contents of clover when offered pairs of swards varying in height and proportion of grass and clover indoors (Illius et al, 1992). Sheep tend to prefer patches with the highest biomass per unit area on Australian annual pastures (Arnold, 1987). Cattle avoid short dense ryegrass patches when offered a tall and dense alternative, but prefer the short dense patches when the alternative is short and sparse (Distel et al, 1995); this confirms that animals generally prefer the swards they can eat fastest (Black and Kenney, 1984). An exception, however, is the $70 \%$ preference of sheep for white clover, mentioned earlier. Clover can be grazed faster than grass (Penning et al, 1991), but sheep do not choose it exclusively. Several explanations for this preference for a mixed diet (nutritional basis, maintenance of rumen microflora, sampling) have been discussed in depth by Newman et al (1992) and Parsons et al (1994a). An alternative explanation has recently been proposed by Newman et al (1995). These authors have developed a model in which the optimal diet for sheep is often a mixture of grass and clover. Their model suggests this would be an optimal trade-off between relative intake rates and absorption rates, and to a lesser extent, passage rates.

Sward height does not affect the preferences of animal species differing in body size or grazing style to the same extent. When sheep, cattle and goats were offered pairs of ryegrass strips previously mown to different heights, all species strongly preferred the taller sward (Illius and Gordon, 1990). However, cattle further restricted by the reduction of their bite depth on the shortest swards (Illius and Gordon, 1987) chose the taller strip more readily than did sheep. Goats that took shallow bites from the sward surface had the strongest preference for the taller strip. Sheep also had a higher preference than cattle for vegetative cocksfoot swards associated with reproductive ones (Dumont et al, 1995a, c). Sheep tried to maintain their high preference for the vegetative patches as sward height was reduced, whereas cattle switched to reproductive ones (fig 1). To carry on this comparative study on the preferences of sheep and cattle, Dumont and Petit (1995) developed an indoor test in which the animals could feed either on a poor quality forage available ad libitum, or walk back and forth across the test area for limited quantities of a good quality one. The two species were rewarded with quantities of a regrowth hay corresponding to equal proportions of their intake capacity. As the animals ingested all the regrowths each time they reached them, preference estimates were not confounded by differences in the ability to make selective bites. The late-cut fescue available ad libitum was also chopped to limit selective feeding. This method thus makes it possible to compare the preferences of sheep and cattle in ideal conditions. Results confirmed 


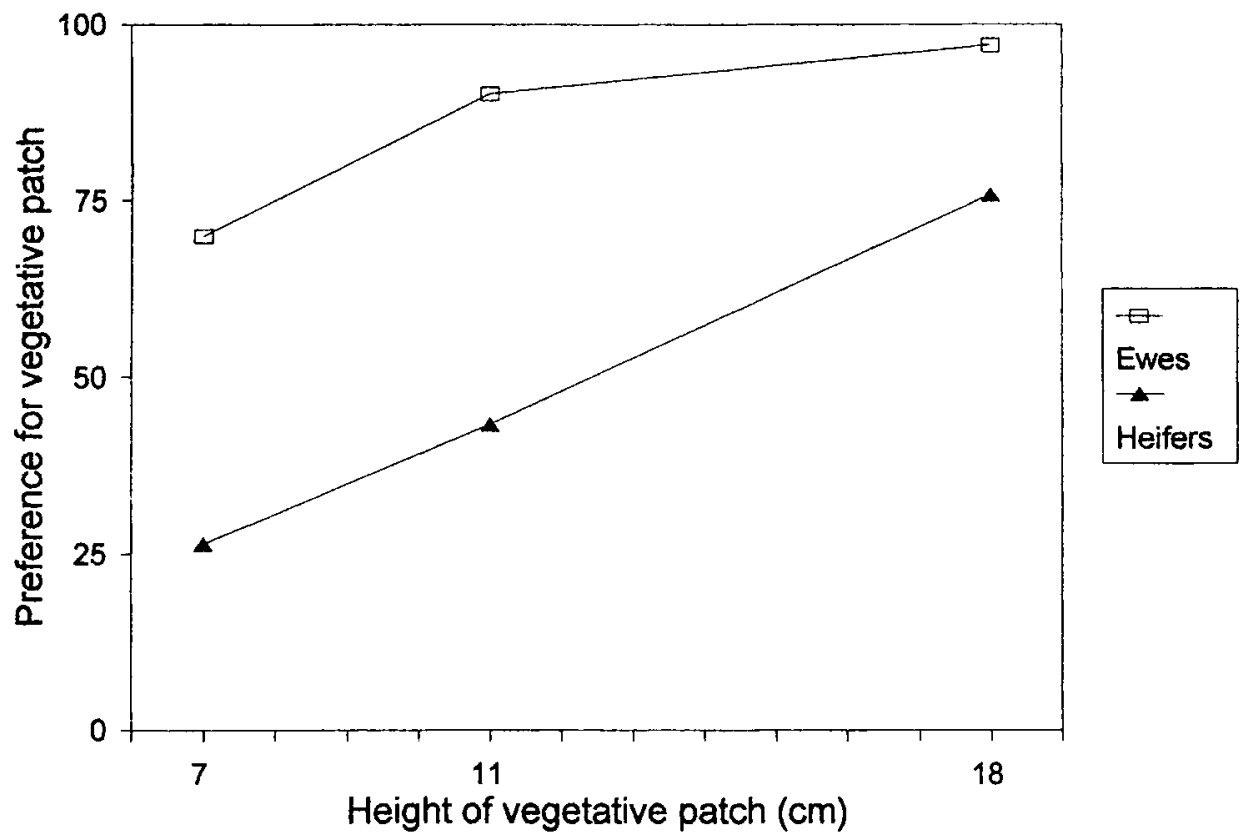

Fig 1. Effect of height of vegetative sward on the relative preference of heifers and ewes (\% of grazing time) for a vegetative cocksfoot patch associated with a reproductive one (from Dumont et al, 1995a,c).

that sheep have a higher preference than cattle for leafy forages relative to stemmy ones.

Within each species dietary preferences can be affected by various factors. Although the physiological state largely determines the energy requirements of herbivores, there is no experimental evidence that it can influence preferences. Newman et al (1995) used their model to assess how intake rates of grass and clover affect the preferences of dry and lactating ewes. They found many cases in which the proportion of clover in the optimal diet for a lactating ewe was higher than that in the optimal diet for a dry ewe. However, in experimental conditions, dry and lactating ewes did not significantly differ in their relative preference for grass and clover (Parsons et al, 1994a). Lactating ewes spent 69,64 and $58 \%$ of their grazing time on clover on the first, third and sixth day in the plot, versus 59,54 and $53 \%$ of grazing time for the dry ewes. On the other hand, fasting influenced the preferences of grazing sheep. Ewes spent less time grazing on clover ( 82 vs $92 \%$ ) and more time grazing on grass after a 24-h fast (Newman et al, 1994) in spite of their higher intake rate on clover. The more they were fasted, the more young ewes grazed reproductive cocksfoot patches associated with vegetative ones (Dumont et al, 1995c; fig 2). It seems that in sheep, short-term feed restriction due to fasting thus entails a stronger response in the animal than long-term increasing energy demand. Conversely, a fast up to $24 \mathrm{~h}$ did not affect the heifers' choice between vegetative and reproductive cocksfoot strips (Dumont et al, 1995c). 


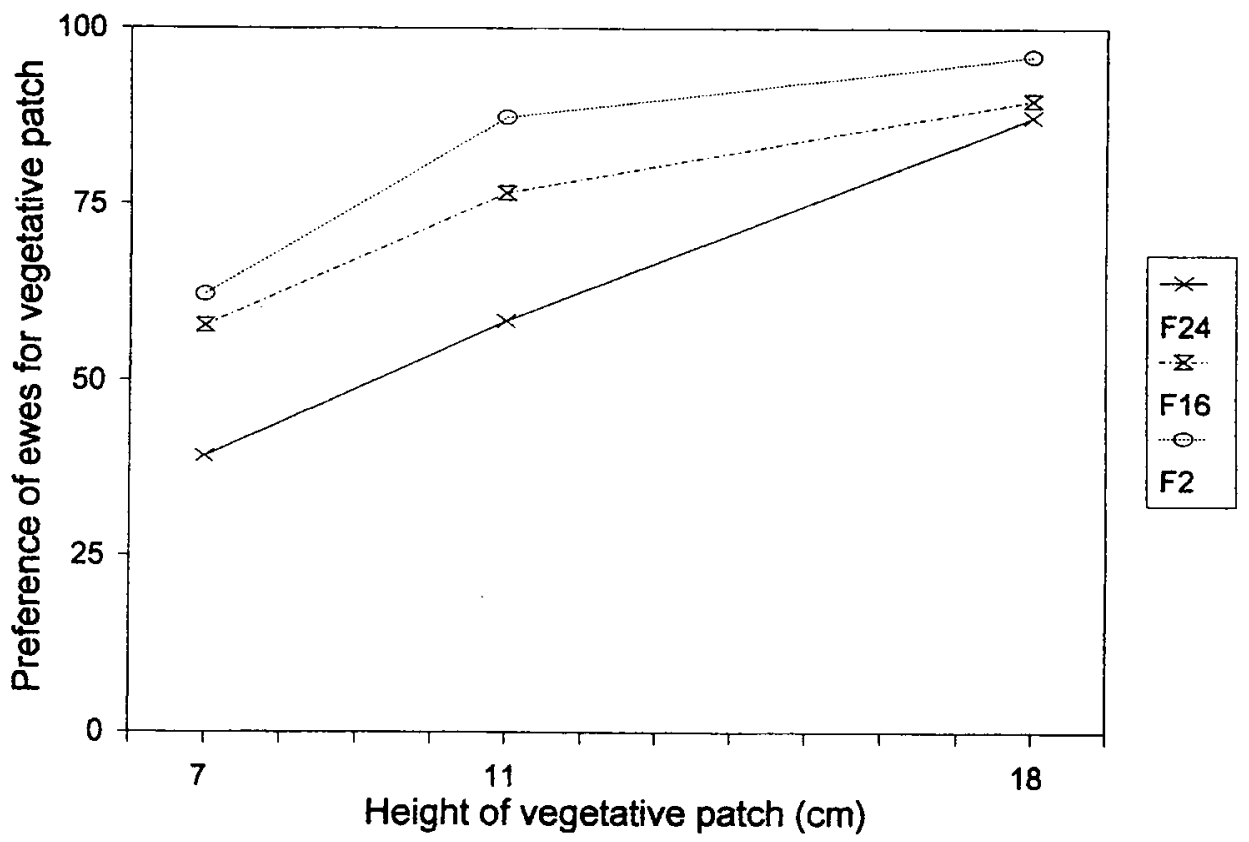

Fig 2. Effect of fasting on the relative preference of ewes (\% of grazing time) for a vegetative cocksfoot patch associated with a reproductive one (from Dumont et al, 1995c). F24: 24 h fast; F16: 16 h fast; F2: unfasted.

Previous grazing experience can also affect the preferences of herbivores. Lambs that had been exposed to either grass or clover pastures for 1 week, $1 \mathrm{~h}$ each day, before or during weaning, developed a stronger preference for the species they were familiar with (Ramos and Tennessen, 1992). Four weeks after weaning, clover-experienced lambs spent $69 \%$ of their grazing time on clover versus $45 \%$ of grazing time for those that had experienced ryegrass. Recent grazing experiences with well-known forages can temporarily affect the choice of adult animals in an opposite way. Ewes that had been grazing for a minimum of 2 or 3 weeks on either ryegrass or clover monocultures were later tested for their choice between the two plant species. The animals initially showed an increased preference for the species other than the one they had been grazing (Newman et al, 1992; Parsons et al, 1994a), but after 3 days the animals reverted to a preference for their background diet (Parsons et al, 1994a; fig 3). Finally, Orr et al (1995) tested the choice of lambs and kids between ryegrass and white clover patches, the animals being either reared naturally or cross fostered between animal species. Three weeks after weaning, lambs reared by goats tended to have a lower preference for clover than did lambs reared by ewes ( 38 vs $45 \%$ of grazing time), and kids reared by ewes tended to have a greater preference for clover than did kids reared by goats ( $65 \mathrm{vs}$ $44 \%$ of grazing time). As sheep tend to have a greater preference for clover than goats, these results demonstrate that the experi- 


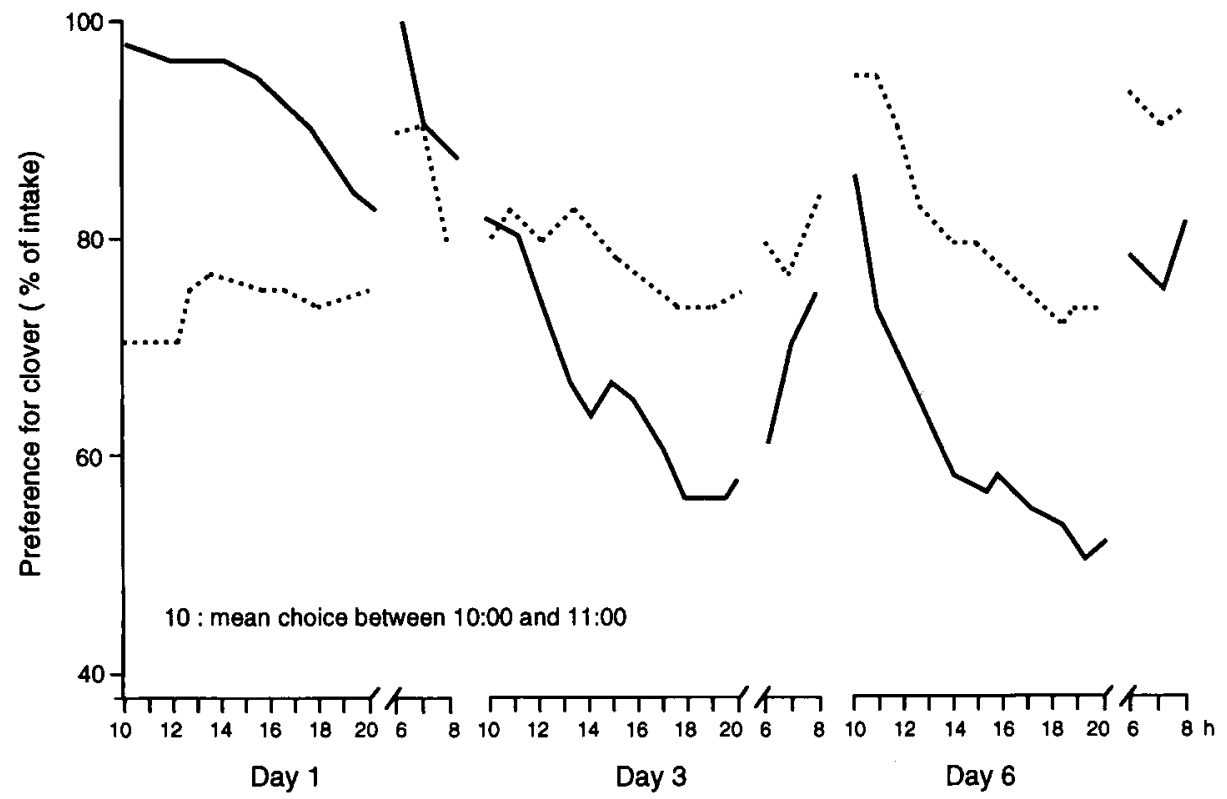

Fig 3. Effect of a recent diet (species grazed for 2-3 weeks before measurements) on the preference of ewes (\% of intake) for clover compared to ryegrass (from Parsons et al, 1994a). Solid line: ewes from a grass 'background'; clotted line: ewes from a clover 'background'.

ence of grazing with social models can influence dietary preferences.

There were also individual variations in preferences within groups of sheep or cattle offered adjacent strips of vegetative and reproductive cocksfoot swards for $30 \mathrm{~min}$ (Dumont et al, 1995a, c). With the same animals always tested together (in groups of three or four), the widest range of individual preferences for reproductive sward was 27 to $50 \%$ in ewes and 25 to $52 \%$ in heifers. However, when the choices of nine ewes and nine heifers were observed over a whole day, they ranged much less widely: preference for reproductive sward ranged from 6 to $19 \%$ in ewes and from 39 to $56 \%$ in heifers (Dumont et al, 1995a). Finally, consistent diurnal patterns of preferences are frequently observed in herbivores. Rumi- nants may be more willing to consume forages of slower digestion and passage rates in the late evening because rumination takes place during the night. Sheep consumed more clover and less grass in the morning than in the evening (Newman et al, 1994; Parsons et al, 1994a; fig 3), and this tactic was predicted to be optimal by Newman et al (1995). Sheep spent more time feeding on the reproductive sward during the last evening meal (Dumont et al, 1995a). However, in the same experiment sheep also increased their preference for the reproductive sward in the early morning, and cattle had constant choices over the whole day. Ruminants also seem to have a higher preference for browse in the morning. Both sheep and deer tend to graze more heather in the early morning and more grass later in 
the day (Clarke et al, 1995). Similarly, llamas feeding on a Mediterranean shrubland consumed high proportions of browse in the morning, then spent most of their grazing time on grass patches (Dumont et al, 1995b).

In conclusion, both forage species and plant structure affect dietary preferences of herbivores at pasture. Animal species generally differ in their preferences, and within each species, fasting and previous grazing experience have an additional effect. The extent of individual variations in preferences requires further study. Finally, consistent diurnal patterns of preferences are frequently observed in herbivores. After this review of what the animals choose to eat given a minimum of constraints, we will now focus on how vegetation constraints and limits in foraging ability of herbivores can affect preference expression in grazing conditions.

\section{FACTORS LIMITING PREFERENCE EXPRESSION}

\section{Vegetation constraints}

Nearly all the results mentioned earlier were obtained with the same area of the different sward types offered to the animals. Newman et al (1994) did not find any effect of clover abundance ( 20 vs $80 \%$ of plot area) on the choice of dry ewes between ryegrass and white clover monocultures; the animals spent, on average, 75 and $76 \%$ of their grazing time on clover in the two treatments. Conversely, Parsons et al (1994a) found that the ewes spent less time grazing clover on swards of $20 \%$ clover compared with swards of 50 and $80 \%$ clover (44 vs 73 and $67 \%$ of grazing time). Inconsistent results between the two experiments may be due to differences in sward structures (see Newman et al, 1995). However, Parsons' results clearly show that forage abundance can affect preference expression. In cattle, Penning et al (1995b) did not find any significant effect of clover abundance (25 vs $75 \%$ ) on heifers' preference, though the animals tended to spend more time grazing clover in the $75 \%$ clover treatment ( 77 vs $52 \%$ of grazing duration).

On pastures and rangelands, vegetation constraints become important because they alter rates of encounter of preferred forages. The availability of the different sward components can limit preference expression. The less available a component is, the less it generally enters into the animals' diet. For example, the proportion of clover in the diet of sheep grazing mixed grass-clover swards decreases with the percentage of clover in the sward (Milne et al, 1982; Clark and Harris, 1985). Herbivores broadly switch to the plant species which are most available as the availability of their preferred species decreases (Launchbaugh et al, 1990; Dumont et al, 1995b; O'Reagain and Grau, 1995), and this helps them to maintain constant intake.

The influence of the spatial distribution of forage patches on dietary choices has recently been studied. Edwards et al (1994) observed the diet sheep selected when offered 100 equidistant bowls of a homogeneous mixture of cereal and straw pellets, each bowl containing either a high or a low proportion of cereal pellets which are preferred pellets. Bowls were grouped together to create aggregations of one, two, five or ten bowls and these aggregations were randomly assigned to positions in a vegetationfree field. The proportion of cereal pellets in the diet was higher at the largest scale of aggregation, and this clearly demonstrates that distribution of the food resource can affect diet selection. At pasture, Armstrong et al (1993) confirmed that the proportion of plot area covered by grass-clover patches within a ryegrass sward influences the dietary clover proportion in sheep, but there was no evidence that patch distribution (patches of various sizes $12 \mathrm{~m}$ apart vs $4 \times 4 \mathrm{~m}$ patches separated by various distances) had any additional effect on diet 
composition. Clarke et al (1995) offered sheep and deer plots of heather containing $20 \%$ by area of Agrostis/Festuca sward, distributed in one large, four medium or 12 small patches. Patch distribution did not influence the time deer spent grazing on heather. Conversely, increasing the fragmentation of the available grass clearly encouraged sheep to graze heather more (43 vs $9 \%$ of grazing time) probably because the animals encountered more heather as they moved between grass patches.

\section{Foraging abilities of herbivores}

Herbivores that have a broad and flat muzzle have a lesser ability to feed selectively than species with narrow mouths and incurved incisor arcades (Gordon and Illius, 1988). This ability to sort one food from the others affects diet selection. In the South African veld, cattle avoid grass species with a high proportion of stems and few leaves. Conversely, stemminess does not reduce acceptability of these species to the same extent in sheep, mainly because their narrow muzzle enables them to select leaves and avoid stems (O'Reagain and Stuart-Hill, 1991). More generally, differences in the ability to feed selectively emerge when the animals graze plant communities where high quality components are rare or difficult to harvest. The digestibility of the diet selected by large herbivores like cattle is then markedly lower than that of the diet selected by small herbivores like sheep (fig 4).

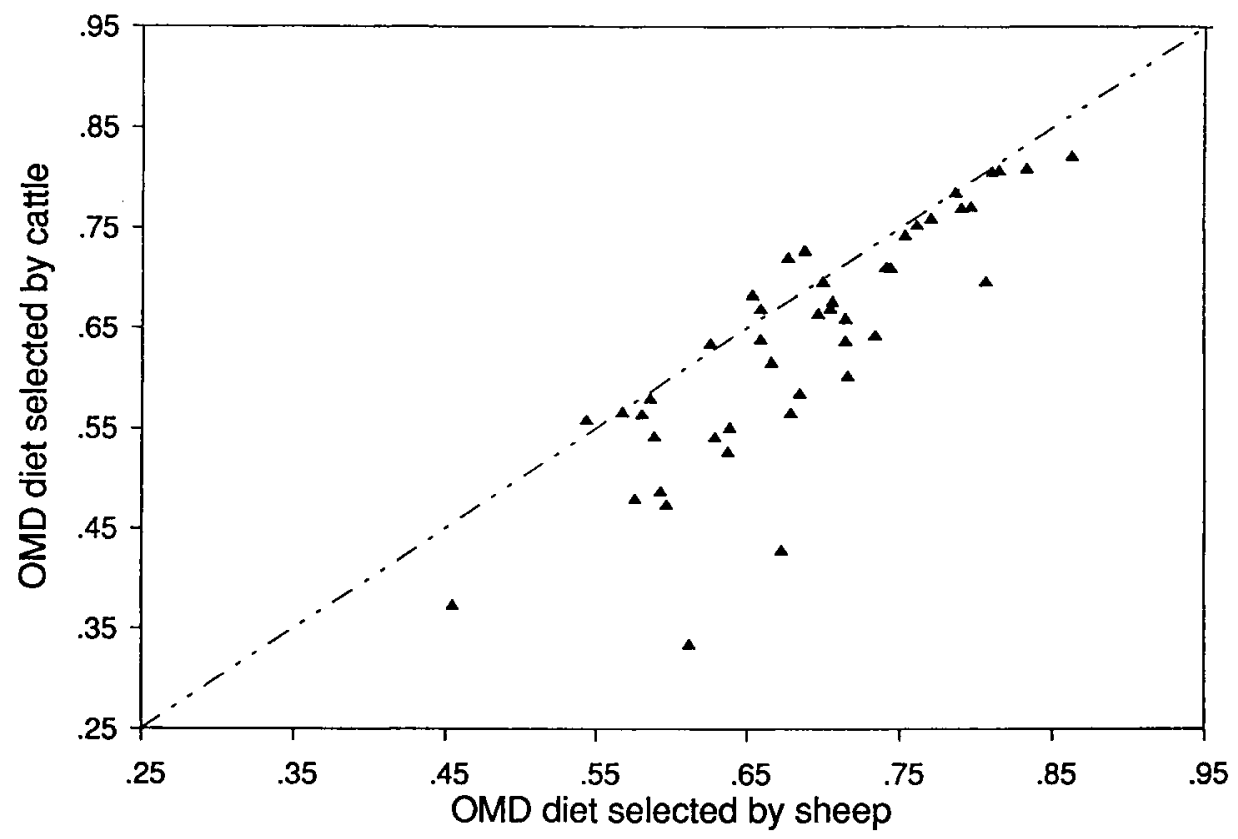

Fig 4. In vitro organic matter digestibility (OMD) of a diet selected by sheep and cattle grazing on the same simple vegetation communities. We have considered that in vitro OMD $(\%)=$ in vitro dry matter digestibility $(\%)+3 \%$ (data from Dudzinski and Arnold [1973], Langlands and Sanson [1976], Jamieson and Hodgson [1979], Hugues et al [1984], Forbes and Hodgson [1985], Norton et al [1990], Hodgson et al [1991]). 
Sheep have a high ability to sort preferred plant components from others. Parsons et al (1994b) demonstrated in a model that the costs of grazing selectively should have little effect on the diet they select on temperate pastures until the fractional cover of their preferred species becomes less than $20 \%$ of the sward. However, sheep select less white clover and more ryegrass from mixed swards than from adjacent grass and clover strip swards (Clark and Harris, 1985). In other observations of sheep grazing mixed grass-clover swards (eg, Milne et al, 1982), they were also constrained from obtaining their preferred diet (about 70\% clover) in pastures with more than $20 \%$ of the area covered by clover. This supports the principle that, even for sheep, the costs of foraging or the time cost associated with recognizing alternative foods in mixtures will affect diet selection (Parsons et al, 1994b).

It is possible to measure the walking ability of herbivores by recording the distances travelled daily, the walking speeds, or in forced walking trials, the number of encouragements to move forward. Border Leicester and Merino sheep have higher walking abilities than Dorset Horns, and in Dorset Horn $\times$ Merino ewes walking ability is also reduced by pregnancy and lactation (Squires et al, 1972). Tarentaise cows have a greater walking ability than the Montbéliarde and Holstein breeds (D'Hour et al, 1994). Sheep and cattle travel nearly the same distance every day, 0.9 to $26 \mathrm{~km} /$ day for cattle and 0.7 to $14 \mathrm{~km} /$ day for sheep according to size of paddock and vegetation availability (Arnold and Dudzinski, 1978). However, the two species explore large paddocks with physical or visual constraints differently. Sheep, being smaller, have a smaller field of vision than cattle and this affects their behaviour: they often walk parallel to fences and sometimes fail to find water or areas with high quality forages (Arnold and Dudzinski, 1978). It is clear from these observations that herbivores can differ in walking ability and in the way they explore large areas. The ability to walk long distances (or to walk quickly) enables animals to explore wider areas and influences their encounter rates of preferred species. Thus, it can affect diet selection.

How herbivores learn and remember the location of food patches determines the extent to which feeding site selection differs from random, and thus influences the diet that the animals select. Cattle can remember the location of food patches in parallel and radial arm mazes and will seldom visit a previously entered arm where they have already consumed grain (Bailey et al, 1989a, b). Both sheep (Edwards, 1994) and deer (Gillingham and Bunnell, 1989) become better at finding food patches (or preferred food patches) as the result of experience with a particular food distribution (fig 5). When the food spatial distribution is altered, the animals initially search for food where it was located previously, but then generally quickly learn the new distribution (Bailey et al, 1989b; Gillingham and Bunnell, 1989; Edwards, 1994). Furthermore, sheep can use associations between pasture cues and rewards to direct their foraging, thus increasing their encounter rate with food patches or preferred food patches (Edwards, 1994). Thus, cattle, sheep and deer have the ability to learn and remember the spatial location of food patches. However, the limits of their spatial memory are not known, and it is not certain that animals can remember the location of preferred patches in areas where they have not been grazing for a long time. Moreover, even in well-known pastures, herbivores forage in a flock and thus always run the risk of returning to a patch that has been depleted by other animals. Imperfect knowledge of forage distribution and competition within the flocks will thus constrain the utilisation of preferred forages at pasture. 


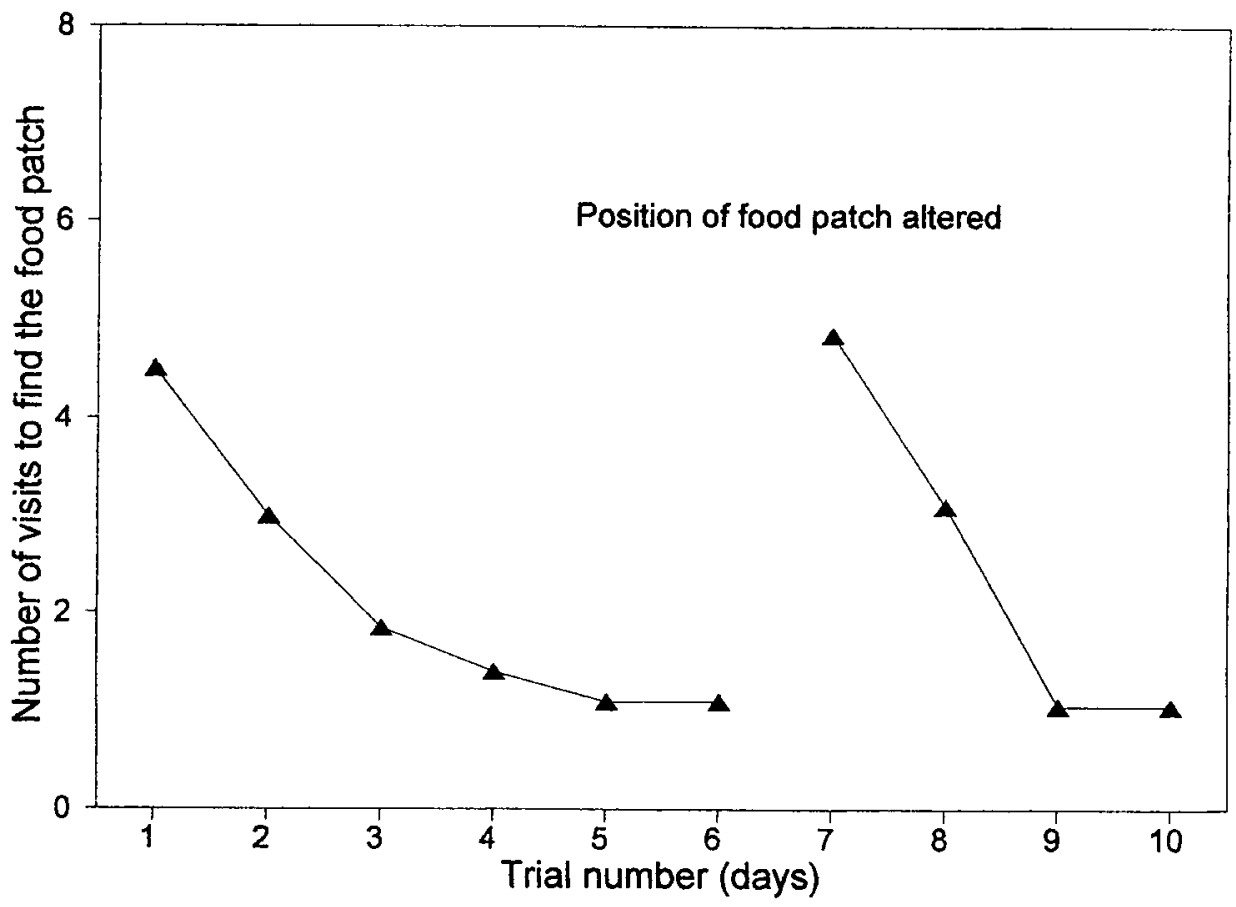

Fig 5. The number of visits required to find the food patch from eight plastic bowls, one containing pellets, the others empty (from Edwards, 1994). On day 7, the location of the food patch was changed.

\section{CONCLUSION}

The constraints herbivores face while foraging affect the diet they select on pastures and rangelands, justifying a clear distinction between selection and preference, ie, between what the animals eat and what they would eat if given complete freedom of choice. Selection is a function of preference, but it is clearly affected by the abundance or the availability of preferred plant species, and by their spatial distribution. Selection is further influenced by some of the animals' foraging abilities; for example, their ability to sort one food from the others, to walk long distances and to learn and remem- ber the location of food patches. Knowing the relative preference of an animal for pairs of plant species enables us to assess how environmental constraints, such as the spatial distribution of these species, can affect preference expression. A better knowledge of the preferences of different types of animals (species, breed, individuals, animals of different age or in various physiological states) should also help us to understand and predict the diets they will select in various pasture conditions. This knowledge will thus serve in choosing those animals that will best meet practical management goals, and possibly in manipulating sward composition. 


\section{REFERENCES}

Archer M (1973) The species preferences of grazing horses. J Br Grassld Soc 28, 123-128

Armstrong RH, Robertson E, Lamb CS, Gordon IJ, Elston DA (1993) Diet selection by lambs in ryegrass-white clover swards differing in the horizontal distribution of clover. In: Proceedings of the XVII International Grassland Congress, Palmerston North (New Zealand) and Rockhampton (Australia). New Zealand Grassland Association, 715716

Arnold GW (1987) Influence of the biomass, botanical composition and sward height of annual pastures on foraging behaviour by sheep. J Appl Ecol 24, 759772

Arnold GW, Dudzinski ML (1978) Ethology of Freeranging Domestic Animals. Elsevier, Amsterdam, $198 \mathrm{p}$

Bailey DW, Rittenhouse LR, Hart RH, Richards RW (1989a) Characteristics of spatial memory in cattle. Appl Anim Behav Sci 23, 331-340

Bailey DW, Rittenhouse LR, Hart RH, Swift DM, Richards RW (1989b) Association of relative food availabilities and locations by cattle. J Range Manage $42,480-482$

Black JL, Kenney PA (1984) Factors affecting diet selection by sheep. II. Height and density of pasture. Aust J Agric Res 35, 565-578

Clark DA, Harris PS (1985) Composition of the diet of sheep grazing swards of differing white clover content and spatial distribution. New Zealand J Agric Res 28, 233-240

Clarke JL, Welch D, Gordon U (1995) The influence of vegetation pattern on the grazing of heather moorland by red deer and sheep. I. The location of animals on grass/heather mosaics. J Appl Ecol 32, 166-176

Crawley MJ (1983) Herbivory: the Dynamics of Animal-Plant Interactions. Univ California Press, Berkeley, CA, $437 \mathrm{p}$

Demment MW, Greenwood GB (1988) Forage ingestion: effects of sward characteristics and body size. J Anim Sci 66, 2380-2392

D'Hour P, Hauwuy A, Coulon JB, Garel JP (1994) Walking and dairy cattle performance. Ann Zootech $43,369-378$

Distel RA, Laca EA, Griggs TC, Demment MW (1995) Patch selection by cattle: maximization of intake rate in horizontally heterogeneous pastures. Appl Anim Behav Sci 45, 11-21

Dudzinski ML, Arnold GW (1973) Comparisons of diets of sheep and cattle grazing together on sown pastures on the southern tablelands of New South Wales by principal components analysis. Aust $J$ Agric Res 24, 899-912
Dumont B (1995) Déterminisme des choix alimentaires des herbivores au pâturage : principales théories. Inra Prod Anim 8, 285-292

Dumont B, Petit M (1995) An indoor method for studying the preferences of sheep and cattle at pasture. Appl Anim Behav Sci 46, 67-80

Dumont B, D'Hour P, Petit M (1995a) The usefulness of grazing tests for studying the ability of sheep and cattle to exploit reproductive patches of pastures. Appl Anim Behav Sci 45, 79-88

Dumont B, Meuret M, Prud'hon M (1995b) Direct observation of biting for studying grazing behavior of goats and llamas on garrigue rangelands. Small Rum Res 16, 27-35

Dumont B, Petit M, D'Hour P (1995c) Choice of sheep and cattle between vegetative and reproductive cocksfoot patches. Appl Anim Behav Sci 43, 1-15

Edwards GR (1994) The creation and maintenance of spatial heterogeneity in plant communities: the role of plant-animal interactions. PhD thesis, Univ Oxford, Oxford, UK, $179 \mathrm{p}$

Edwards GR, Newman JA, Parsons AJ, Krebs JR (1994) Effects of the scale and spatial distribution of the food resource and animal state on diet selection: an example with sheep. J Anim Ecol 63, 816826

Forbes TDA, Hodgson J (1985) Comparative studies of the influence of sward conditions on the ingestive behaviour of cows and sheep. Grass Forage Sci $40,69-77$

Gillingham MP, Bunnell FL (1989) Effects of learning on food selection and searching behaviour of deer. Can J Zool 67, 24-32

Gordon IJ, Illius AW (1988) Incisor arcade structure and diet selection in ruminants. Funct Ecol 2, 15-22

Hanley TA (1982) The nutritional basis for food selection by ungulates. J Range Manage 35, 146-151

Hodgson J (1979) Nomenclature and definitions in grazing studies. Grass Forage Sci 34, 11-18

Hodgson J, Forbes TDA, Armstrong RH, Beattie MM Hunter EA (1991) Comparative studies of the ingestive behaviour and herbage intake of sheep and cattle grazing indigenous hill plant communities. $J$ Appl Ecol 28, 205-227

Hofmann RR (1989) Evolutionary steps of ecophysiological adaptation and diversification of ruminants: a comparative view of their digestive system. Oecologia 78, 443-457

Hughes TP, Sykes AR, Poppi DP (1984) Diet selection of young ruminants in late spring. Proc NZ Soc Anim Prod 44, 109-112

Hunt WF, Hay RJM, Clark D (1989) Pasture species preferences by horses in New Zealand. In: Actes du XVle Congrès International des Herbages, Nice, France, 4-11 Octobre 1989. Association Française pour la Production Fourragère, 797-798 
Illius AW, Gordon IJ (1987) The allometry of food intake in grazing ruminants. J Anim Ecol 56, 989999

Illius AW, Gordon IJ (1990) Constraints on diet selection and foraging behaviour in mammalian herbivores. In: Behavioural Mechanisms of Food Selection (Hughes RN, ed) Springer Verlag, Berlin, 369-393

Illius AW, Gordon IJ (1993) Diet selection in mammalian herbivores: constraints and tactics. In: Diet Selection - An Interdisciplinary Approach to Foraging Behaviour (Hughes RN, ed) Blackwell Scientific Publications, Oxford, 157-181

Illius AW, Clark DA, Hodgson J (1992) Discrimination and patch choice by sheep grazing grass-clover swards. J Anim Ecol 61, 183-194

Jamieson WS, Hodgson J (1979) The effects of variation in sward characteristics upon the ingestive behaviour and herbage intake of calves and lambs under a continuous stocking management. Grass Forage Sci 34, 273-282

Langlands JP, Sanson J (1976) Factors affecting the nutritive value of the diet and the composition of rumen fluid of grazing sheep and cattle. Aust $J$ Agric Res 27, 691-707

Launchbaugh KL, Stuth JW, Holloway JW (1990) Influence of range site on diet selection and nutrient intake of cattle. $J$ Range Manage 43, 109-116

Milne JA, Macrae JC, Spence AM, Wilson S (1978) A comparison of the voluntary intake and digestion of a range of forages at different times of the year by the sheep and the red deer (Cervus elaphus). Br J Nutr 40, 347-357

Milne JA, Hodgson J, Thompson R, Souter WG, Bartham GT (1982) The diet ingested by sheep grazing swards differing in white clover and perennial ryegrass content. Grass Forage Sci 37, 209 218

Nefzaoui A, Ben Salem H, Abdouli H, Ferchichi H (1995) Palatability for goat of some Mediterranean shrubs. Comparison between browsing time and cafeteria technique. Ann Zootech 44 (suppl) 117

Newman JA, Parsons AJ, Harvey A (1992) Not all sheep prefer clover: diet selection revisited. I Agric Sci (Camb) 119, 275-283

Newman JA, Penning PD, Parsons AJ, Harvey A, Orr RJ (1994) Fasting affects intake behaviour and diet preference of grazing sheep. Anim Behav 47, 185 193

Newman JA, Parsons AJ, Thornley JHM, Penning PD, Krebs JR (1995) Optimal diet selection by a generalist grazing herbivore. Funct Ecol 9, 255-268

Norton BW, Kennedy PJ, Hales JW (1990) Grazing management studies with Australian cashmere goats. 3. Effect of season on the selection of diet by cattle, sheep and goats from two tropical grass-legume pastures. Aust J Exp Agric 30, 783 788

O'Reagain PJ, Grau EA (1995) Sequence of species selection by cattle and sheep on South African sourveld. I Range Manage 48, 314-32I

O'Reagain PJ, Schwartz J (1995) Dietary selection and foraging strategies of animals on rangelands. Coping with spatial and temporal variability. In: Recent Developments in the Nutrition of Herbivores (M Journet et al, eds) INRA Editions, Paris, 407-423

O'Reagain PJ, Stuart-Hill GC (1991) The effect of plant structure on the acceptability of different grass species to cattle and sheep grazing african sour grassveld. In: Actes du quatrième congrès international des terres de parcours, Montpellier, France, 22-26 April 1991. CIRAD, Montpellier, 489-491

Orr RJ, Penning PD, Parsons AJ, Harvey A, Newman JA (1995) The role of learning and experience in the development of dietary choice by sheep and goats. Ann Zootech 44 (suppl) 111

Parsons AJ, Newman JA, Penning PD, Harvey A, Orr RJ (1994a) Diet preference of sheep; effects of recent diet, physiological state and species abundance. J Anim Ecol 63, 465-478

Parsons AJ, Thornley JHM, Newman JA, Penning PD (1994b) A mechanistic model of some physical determinants of intake rate and diet selection in a two-species temperate grassland sward. Funct Ecol $8,187-204$

Penning PD, Rook AJ, Orr RJ (1991) Patterns of ingestive behaviour of sheep continuously stocked on monocultures of ryegrass or white clover. Appl Anim Behav Sci 31, 237-250

Penning PD, Newman JA, Parsons AJ, Harvey A, Orr RJ (1995a) The preference of adult sheep and goats grazing ryegrass and white clover. Ann Zootech 44, Suppl, 113

Penning PD, Parsons AJ, Orr RJ, Harvey A, Yarrow NH (1995b) Dietary preference of heifers for grass or clover, with and without romensin slow-release anti-bloat boluses. Anim Sci 60, 550

Provenza FD (1995) Postingestive feedback as an elementary determinant of food preference and intake in ruminants. $J$ Range Manage 48, 2-17

Provenza FD, Balph DF (1990) Applicability of five diet-selection models to various foraging challenges ruminants encounter. In: Behavioural Mechanisms of Food Selection (Hughes RN, ed) Springer Verlag, Berlin, 423-460

Ramos A, Tennessen T (1992) Effect of previous grazing experience on the grazing behaviour of lambs. Appl Anim Behav Sci 33, 43-52

Squires VR, Wilson AD, Daws GT (1972) Comparisons of the walking activity of some Australian sheep. Proc Aust Soc Anim Prod 9, 376-380 